\title{
Determination of Toxic Elements in Tobacco, Tobacco Smoke and Ash from Selected Imported Cigarettes Brands
}

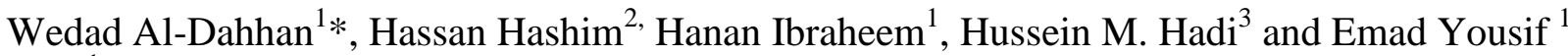 \\ ${ }^{1}$ Department of Chemistry, College of Science, Al-Nahrain University, Baghdad-Iraq. \\ ${ }^{2}$ Department of Physics, College of Science, Al-Nahrain University, Baghdad-Iraq. \\ ${ }^{3}$ Ministry of Education, Baghdad-Iraq. \\ * Corresponding author: dahan6262@gmail.com
}

\begin{abstract}
Metals are essential to the human body but can be harmful to health when it exceeds permissible limits. Different sorts of cigarettes were chosen from the markets in Iraq to conduct the tests of the elements in these species. The chose samples were tested using EDX instrument. Results demonstrated the presence of the proportions of dangerous elements such as $(\mathrm{Sb}, \mathrm{Ni}, \mathrm{Zn}, \mathrm{P}, \mathrm{Pb}, \mathrm{Cd}$, $\mathrm{Ca}, \mathrm{Si}, \mathrm{S}, \mathrm{Cr}, \mathrm{Mg}, \mathrm{Na}, \mathrm{As}, \mathrm{Al}, \mathrm{Cl}$, and $\mathrm{Sn}$ ), which greatly affect the health of the smoker and its negative effects to the environment. The genuine risk is the result of accumulate these elements in the body of the smoker's lungs, liver, blood or brain and its effects are chronic and more dangerous and threatens the life of the person in the future. A special absorption system was used to absorb tobacco smoke for the tested samples by deionized water. The remaining ash collected for acid digestion and prepared to atomic absorption analyses. [DOI: 10.22401/ANJS.21.4.04]
\end{abstract}

Keywords: Heavy elements, Cigarette tobacco, Toxic elements, Tobacco ash.

\section{1-Introduction}

There have been many researches and case studies were done [1-6], they are consistent with these researches which were considered within the safety context. Metals are very important for physiological processes in the human body, but can also destroy health when the concentration is exceeds permissible limits. Heavy metals consider as environmental pollution and can be harmful even in low concentrations [7]. In spite of the fact that there is no certain meaning of heavy metals, but it can be described as metals having a density higher than $5 \mathrm{~g} / \mathrm{cm}^{3}$ [8]. Chronic exposure to heavy elements can be hazardous to health. Plants have the ability to accumulate heavy elements in the roots or leaves [9]. Tobacco plants have the ability to transport heavy metal ions from the soil through plant roots to the leaves $[10,11]$. Several heavy metals found in tobacco smoke such as $(\mathrm{Cd}$, $\mathrm{Cr}, \mathrm{Pb}$, and $\mathrm{Ni}$ ) also accumulate in tissues and fluids through smoking [12-18]. Tobacco smoking is the most important single source of $\mathrm{Cd}$ exposure in the general population. Cigarette smoke contains organic and inorganic chemicals. There are more than 4000 chemicals described in tobacco that are harmful to health [19]. Tobacco smoking not just affects the human health, but it is also associated with the environmental contamination. Liquid, solid or even smoky waste is a serious contaminant to the environment. Various researches on pollution of the environment through tobacco. Devices include kretek, bidi and shisha (see Fig.(1)) [20]. This work aims to determine the toxic metals in tobacco, tobacco smoke and ash from selected imported cigarettes brands in Iraq using smoke absorption by deionized water method and examination metals concentration using (EDX) and atomic absorption devices. This research spans a series of research specialized in safety aspects to lay the groundwork for human health and environment [21-25].

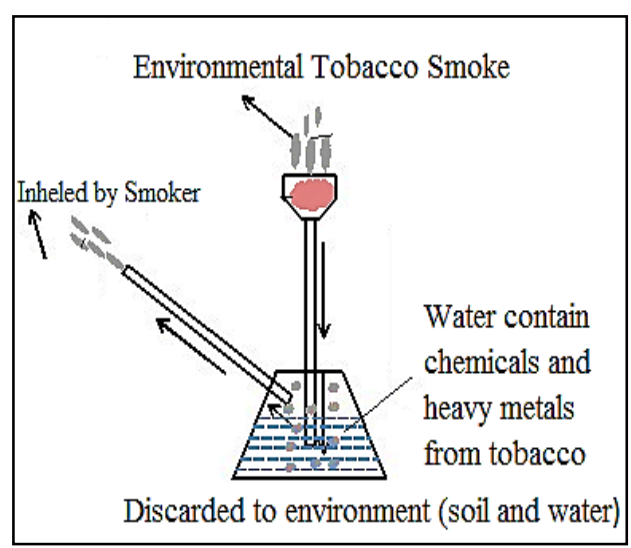

Fig.(1): Shisha (narghile, water pipe). 


\section{2- Experimental part}

\subsection{Samples}

Three samples of common most traded and cheap price brands of cigarettes (1-3) were purchased from Iraqi markets.

\subsection{Tobacco smoke absorption}

A special absorption system consisting of a vacuum pump, control valve and two absorption flasks contains deionized water were collected for the smoke withdrawn from the combustion of tobacco from the three cigarette tobacco samples (see Fig. (2)).

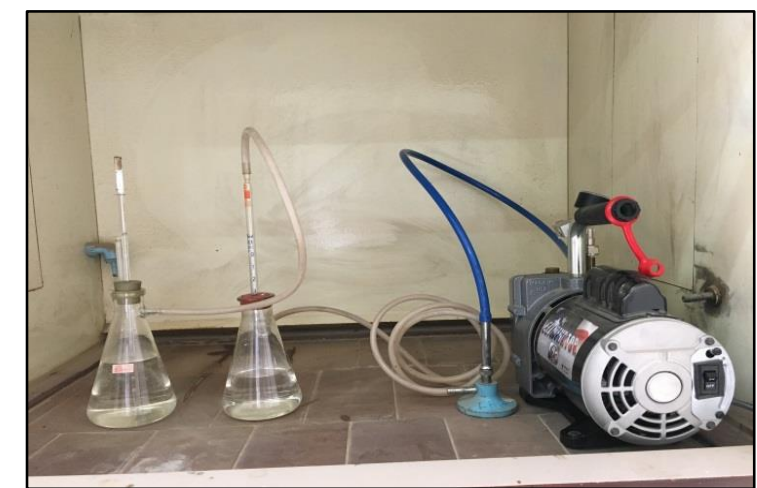

Fig.(2): System for smoke and ash collection.

25 cigarettes from each sample (1,2 and 3). Its weights (13.5,12.2 and 13.1) g respectively, used for smoke and ash collection using the system which previously described in sec.2.2. Smoke was absorbed with deionized water. The resulting solution was collected Fig.(3) to be used for various metal analyses and the remaining ash collected for each sample was $(2.7,2.65$ and 2.82) g respectively (see Fig.(4)) for the use in EDX metal analyses tests and to be acid digested later for atomic absorption metal concentration analyses.

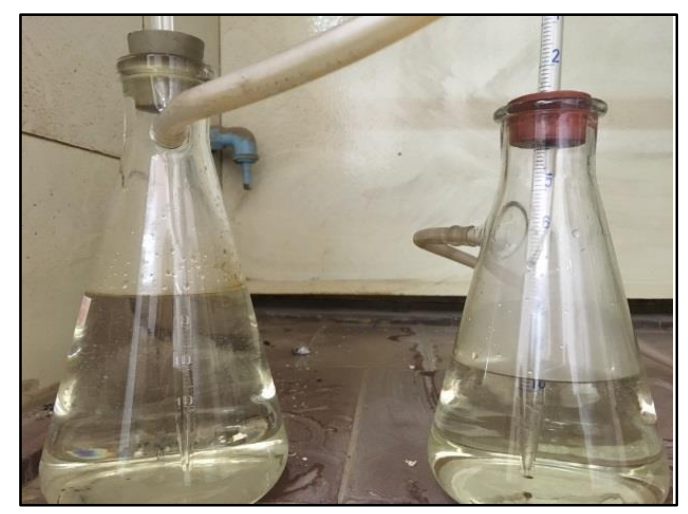

Fig.(3): Absorption flasks.

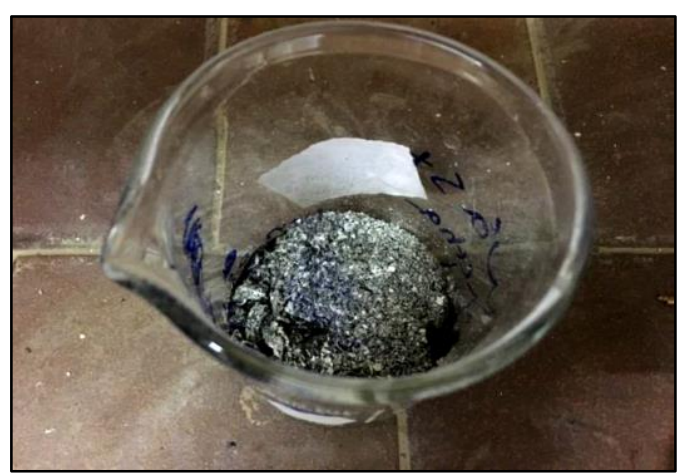

Fig.(4): Remaining ash.

\subsection{Digestion of Tobacco Ash Samples}

The remaining ash collected for each sample which was $(2.7,2.65$ and 2.82) $\mathrm{g}$ for the samples (1,2 and 3 ) respectively was placed separately into a beaker of $500 \mathrm{ml}$ in volume and $20 \mathrm{ml}$ of di - acid mixture of hydrochloric acid and perchloric acid with ratio 2.5: 1 with mixing [26] to free the metals that could be determined by the atomic absorption apparatus (AAS). Contents then cooled and filtered through Whatman 1filter paper and the volume made up with deionized water to $100 \mathrm{ml}$. Spectrophotometric metal determination can be done for the prepared solution.

\subsection{Atomic Absorption analysis}

Atomic absorption AAS Agilent FS240 model was used for metal determination and its concentration in the previously water extracted samples and tobacco ash acid digested samples. Standard solutions were prepared in different concentrations for each element to establish the calibration curve according to the detection limits concentration defined in the instrument. Air-Acetylene burner was used to determine metal concentrations in the range of $\mathrm{mg} / \mathrm{kg}$ ( $\mathrm{ppm})$.

\subsection{Energy-dispersive X-ray spectroscopy analysis}

Energy-dispersive X-ray spectroscopy (EDS, EDX, or XEDS) Bruker model XFlash6I10, is an analytical technique we used for the elemental analysis for tobaccos selected types of cigarettes.

\section{3- Results and Discussion \\ 3.1. EDX Results}

\subsubsection{Tobacco results}

Three samples of common brands of cigarettes (1-3) were tested in EDX instrument for elemental determination. Results obtained for these tests illustrated in the Fig.(5,6 and 7) respectively. 


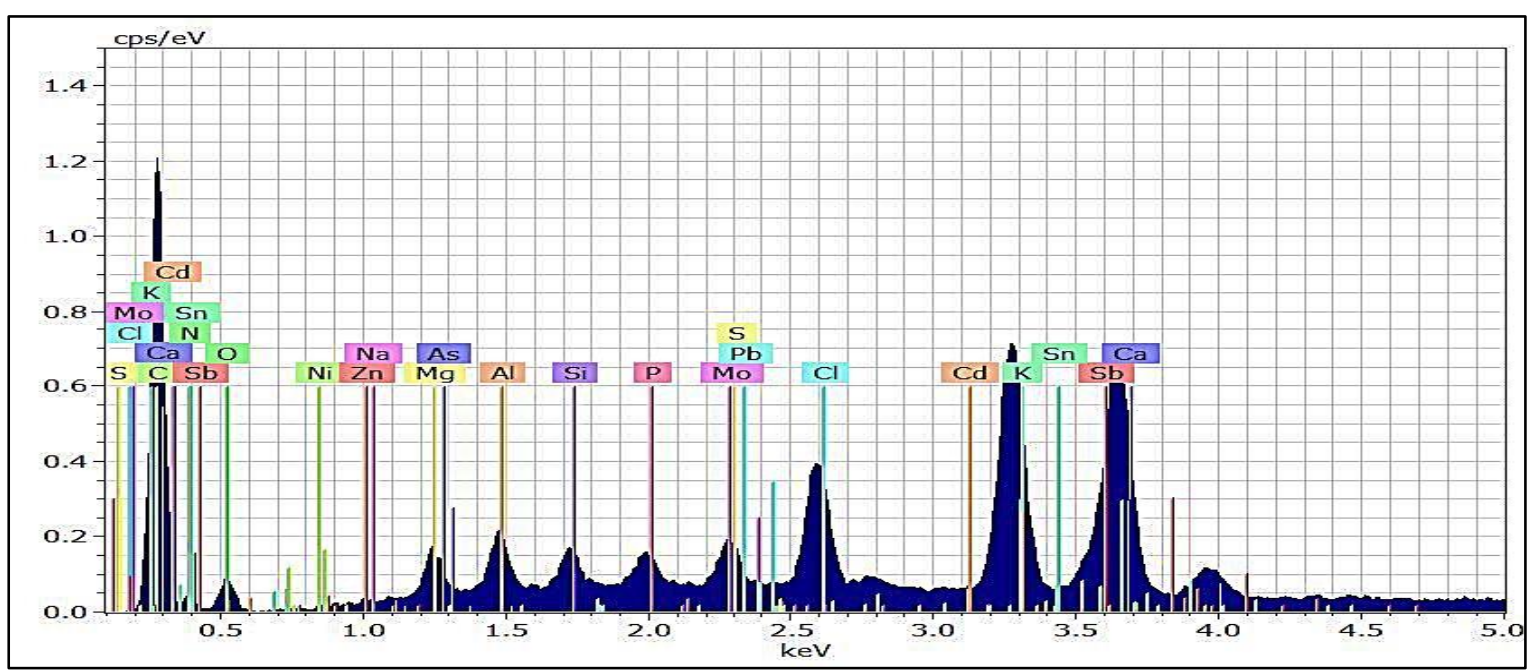

Fig.(5): EDX spectrum for cigarette tobacco- sample -1 .

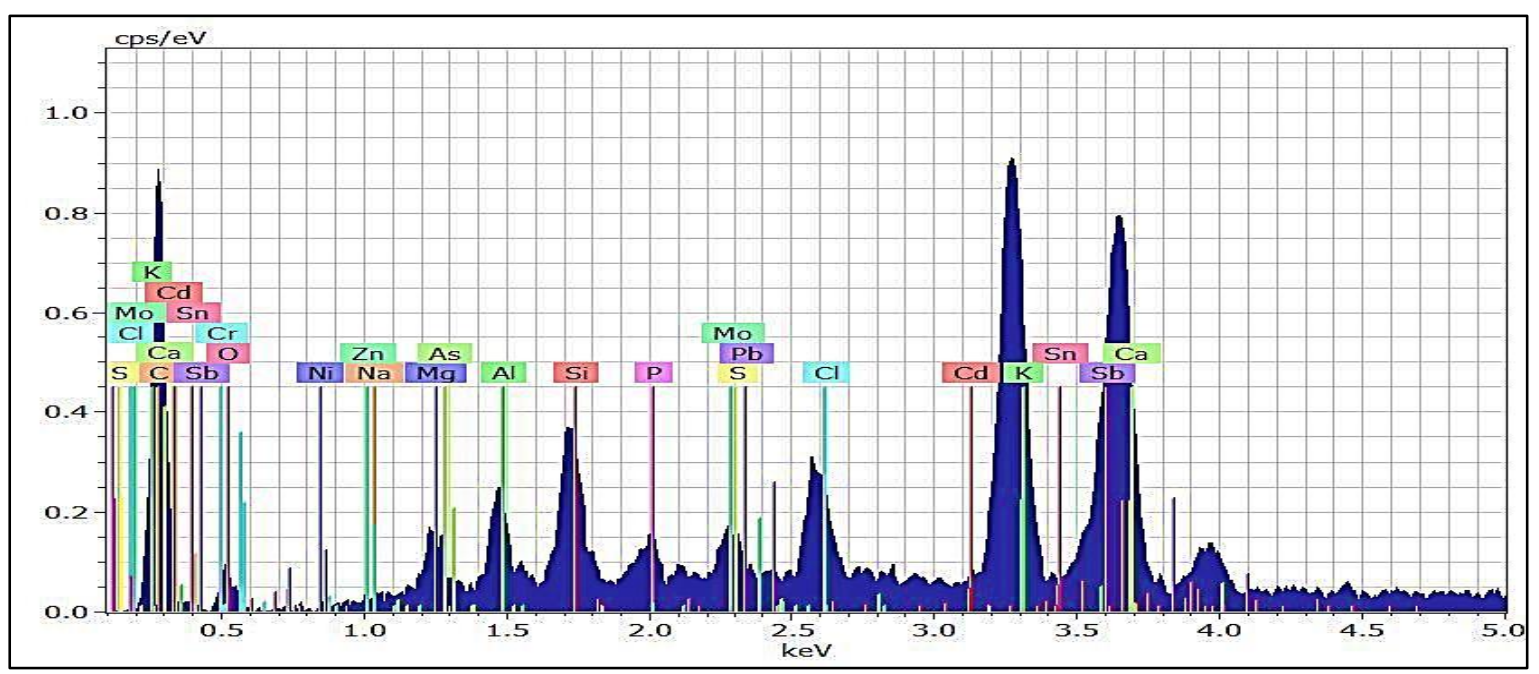

Fig.(6): EDX spectrum for cigarette tobacco- sample -2.

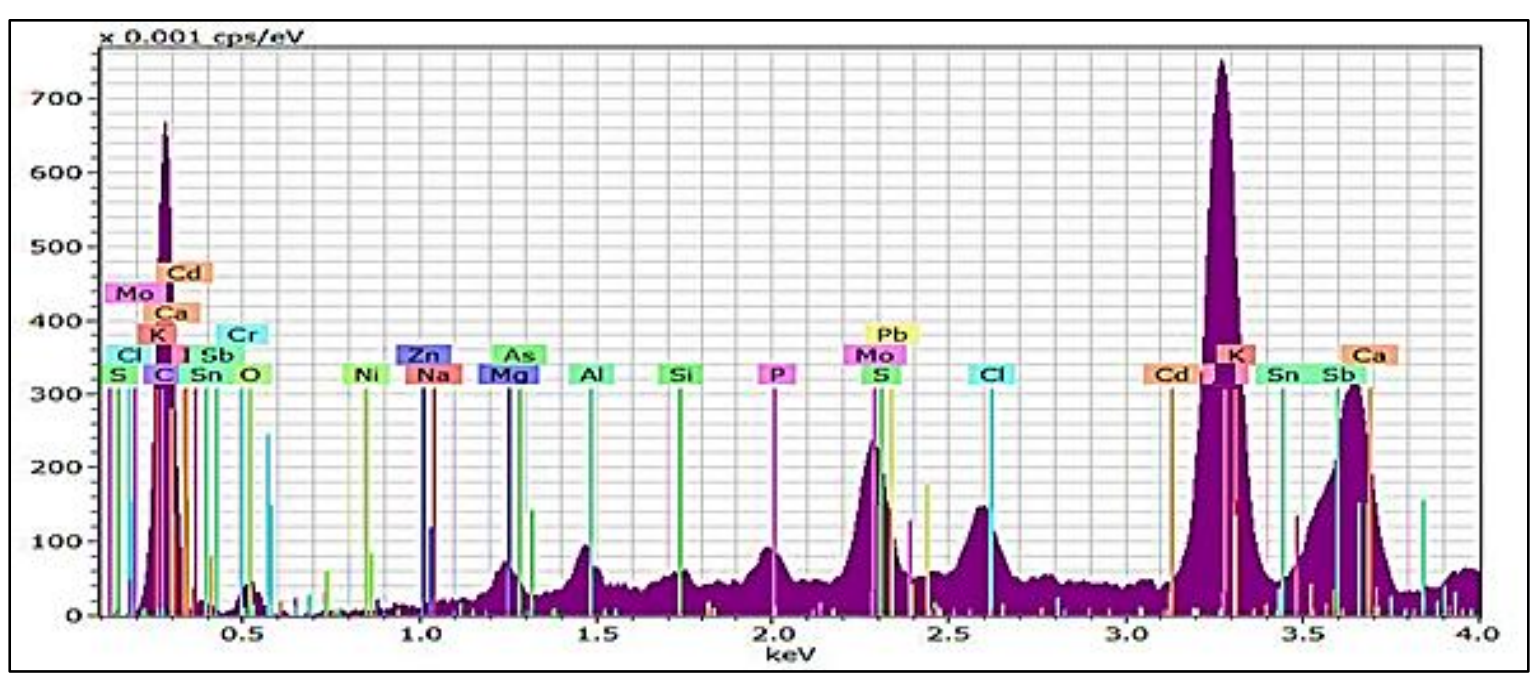

Fig.(7): EDX spectrum for cigarette tobacco- sample -3 .

\subsubsection{Tobacco Ash Results}

After burning the tobacco from the three selected types, ash was collected and homogenized. Samples were taken for (EDX) elemental tests. Results for the three samples
(1, 2 and 3) illustrated in Fig.(8, 9 and 10) respectively. 


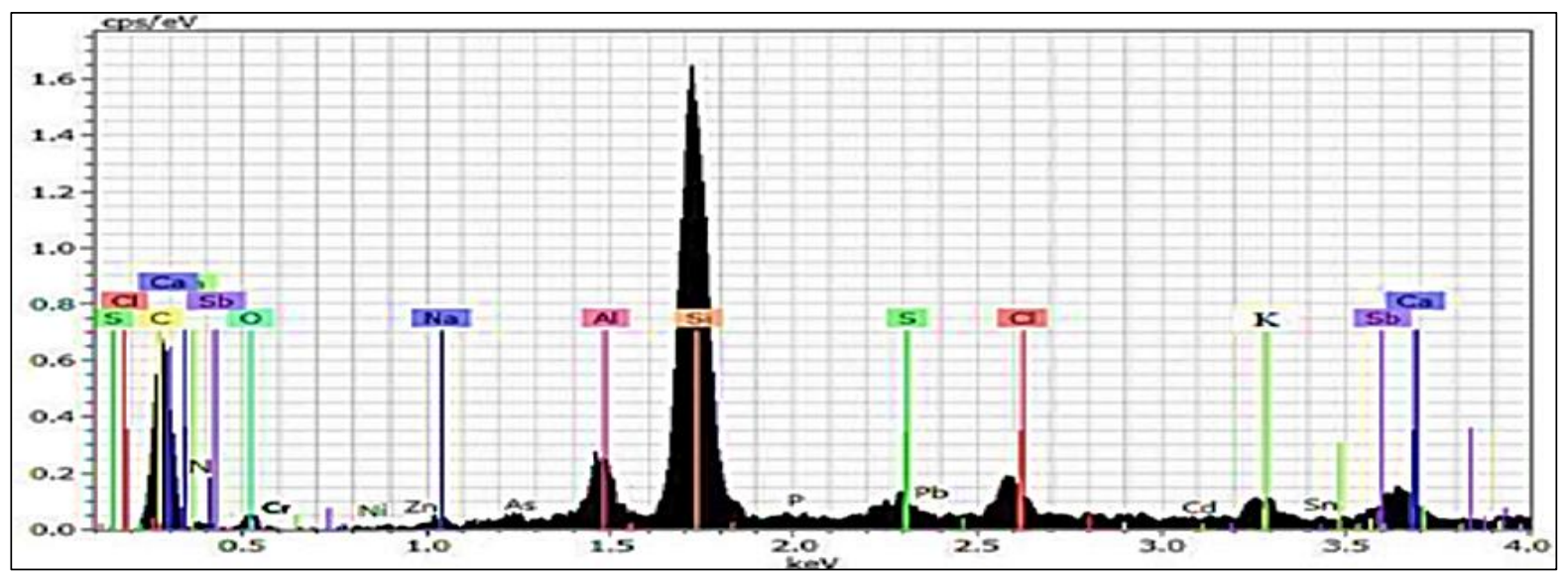

Fig.(8): EDX spectrum for cigarette tobacco ash- sample -1.

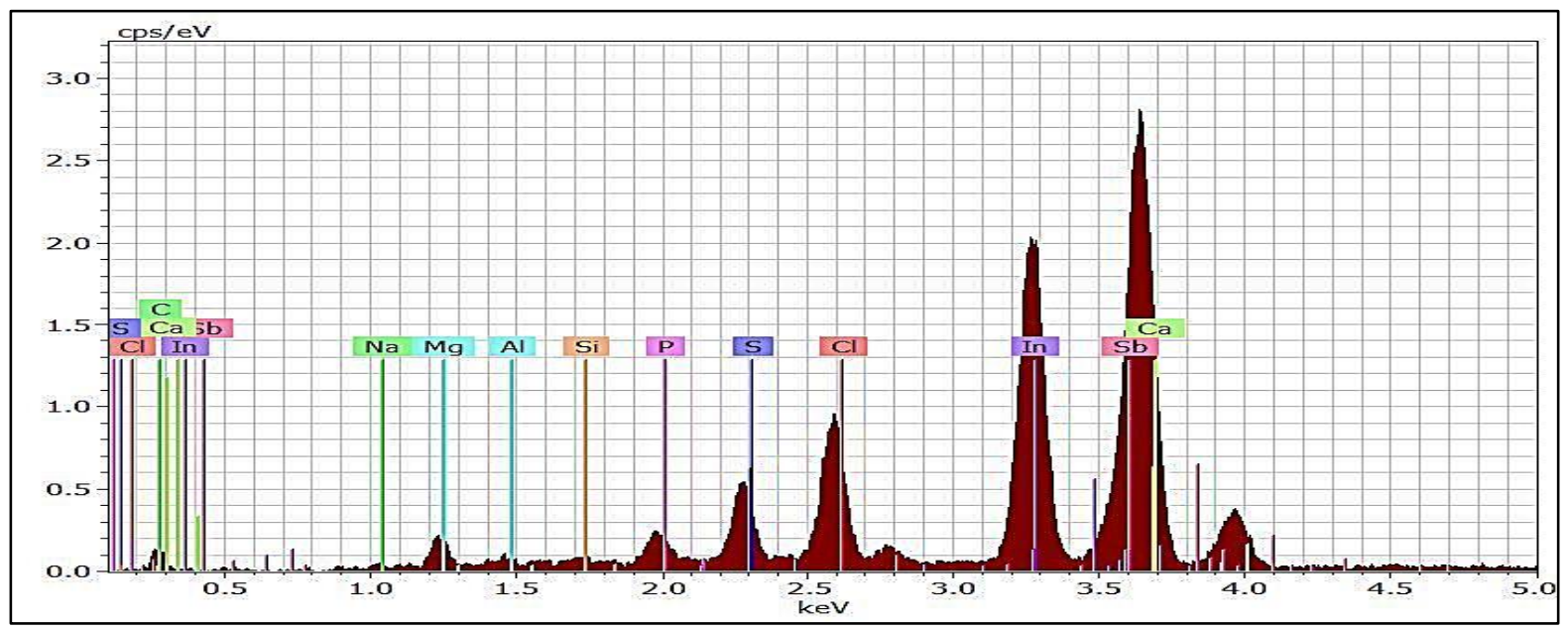

Fig.(9): EDX spectrum for cigarette tobacco ash-sample -2.

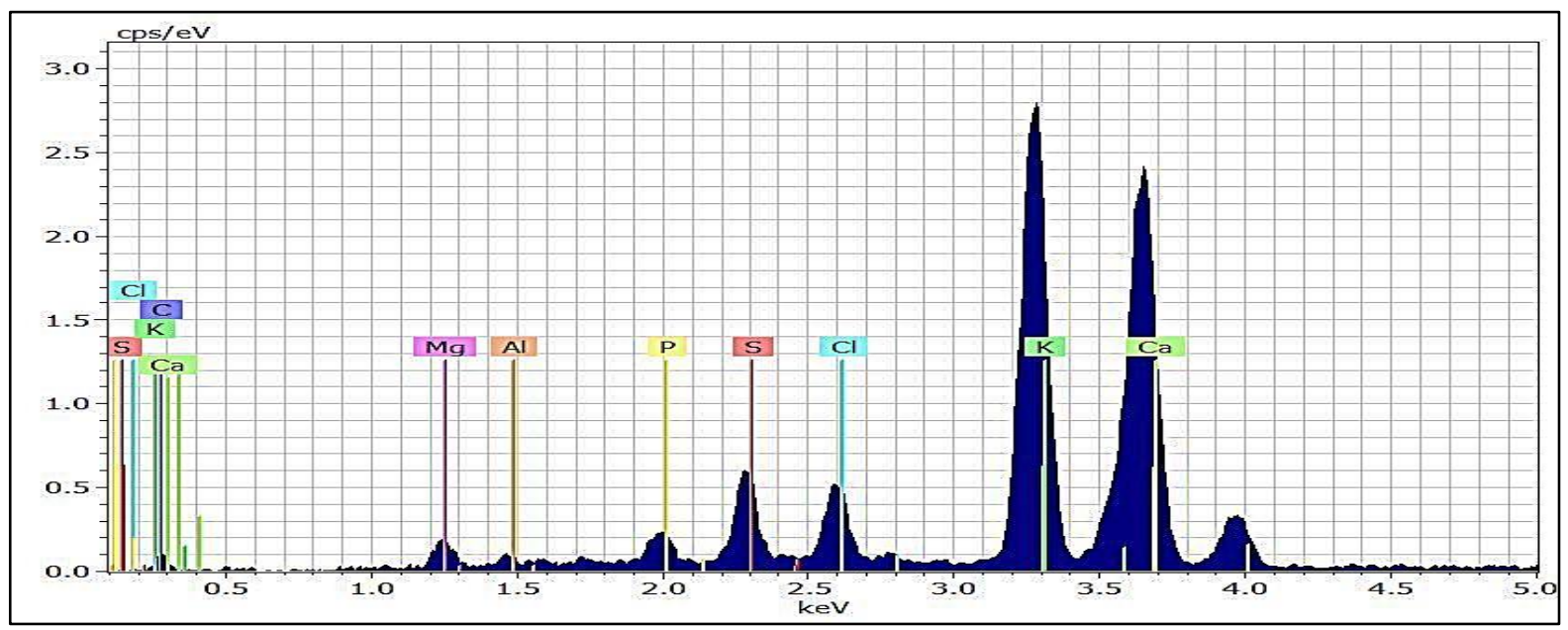

Fig.(10): EDX spectrum for cigarette tobacco ash- sample -3 .

\subsubsection{Absorbed tobacco smoke (EDX)} analysis

The extracted elements in water for one selected type of tobacco (Sample-1) were tested in (EDX) after heating the sample to dryness. Results illustrated in Fig.(11). In this absorption system, the smoker's condition is simulated and what elements it can receive in the smoke inhaled from the cigarette and what remains in the ash. Devices include kretek, bidi and shisha may acts as absorbers [20]. This pollutant is the share of the environment and thus it can be said that the toxic elements have a direct effect on the smoker including the chronic effects [9] as well as its negative effects on the environment through smoke, water and Ashes. 
When comparing the (EDX) analysis (Sample-1) between the original tobacco Fig.(5), the water extract Fig.(11) and the ash Fig.(8), it is clear that the ash contains high concentration of $(\mathrm{Si})$ and a lower concentration of elements (Al, S, K and Ca) and very limited concentrations of the elements ( $\mathrm{Sb}, \mathrm{Ni}, \mathrm{Zn}, \mathrm{P}$, $\mathrm{Pb}, \mathrm{Cd}$ and $\mathrm{Sn}$ ). This indicates that a high concentration of these elements may be absorbed by water through the smoke absorbed from the cigarettes which are $(\mathrm{Sb}, \mathrm{Ni}, \mathrm{Zn}, \mathrm{P}$, $\mathrm{Pb}, \mathrm{Cd}, \mathrm{Ca}, \mathrm{Si}, \mathrm{S}, \mathrm{Cr}, \mathrm{Mg}, \mathrm{Na}, \mathrm{As}, \mathrm{A}$ l, Cl, Sb and $\mathrm{Sn}$ ). These elements represent the amount of the smoker's share, either in the ash, which represents the share of the environment. Most of such elements accumulate in tissues and fluids through smoking [12-18].

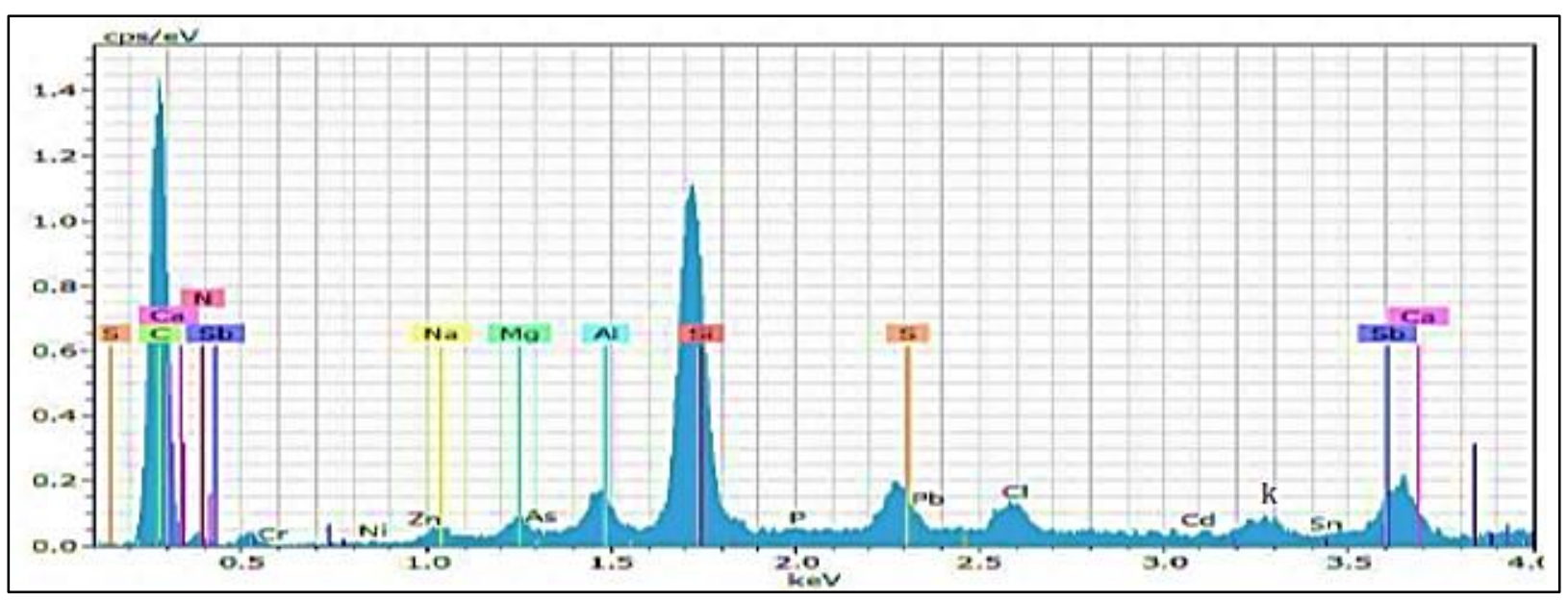

Fig.(11): The extracted elements in water from sample-1 cigarette tobacco smoke.

\subsection{Atomic Absorption analysis}

\subsubsection{Digested tobacco tests}

Some selected elements were tested using atomic absorption apparatus for the digested tobacco samples (1-3). Concentration of some selected elements in $\mathrm{mg} / \mathrm{kg}(\mathrm{ppm})$ for some tobacco prepared samples illustrated in Table(1).

Table (1)

Concentration of selected elements in $\mathrm{mg} / \mathrm{kg}(\mathrm{ppm})$ for some tobacco prepared samples.

\begin{tabular}{|c||c||c|c|c|c|c||c||c||c||}
\hline Sample & Ni & Al & Cr & Mg & Fe & Cd & Zn & K & Pb \\
\hline \hline 1 & 0.10 & 17.0 & $<1$ & 29.7 & $<1$ & $<1$ & 0.12 & 50.00 & $<1$ \\
\hline \hline 2 & 0.11 & 19.0 & $<1$ & 3.38 & $<1$ & $<1$ & 0.06 & 25.00 & $<1$ \\
\hline \hline 3 & 0.13 & 15.5 & $<1$ & 15.3 & $<1$ & $<1$ & 0.82 & 55.00 & $<1$ \\
\hline
\end{tabular}

\subsubsection{The digested tobacco ash tests}

The digested tobacco samples (1-3) were tested. Results are illustrate in Table (2).

Table (2)

The concentration of selected elements in $\mathrm{mg} / \mathrm{kg}(\mathrm{ppm})$ for some digested tobacco ash (1-3) samples.

\begin{tabular}{||c||c||c|c|c|c|c|c|c|c||}
\hline \hline Sample & Ni & Al & Cr & Mg & Fe & Cd & Zn & K & Pb \\
\hline \hline 1 & 0.02 & 10.20 & $<1$ & $<1$ & $<1$ & $<1$ & 0.06 & 6.30 & $<1$ \\
\hline 2 & 0.02 & 11.70 & $<1$ & 1.52 & $<1$ & $<1$ & 0.04 & 4.70 & $<1$ \\
\hline 3 & 0.01 & 7.60 & $<1$ & 6.60 & $<1$ & $<1$ & 0.025 & 3.01 & $<1$ \\
\hline \hline
\end{tabular}




\subsubsection{Absorbed tobacco smoke test}

The absorbed elements from tobacco smoke in water for the samples (1-3) were tested in atomic absorption. Results are shown in Table (3).

Table (3)

The concentration of selected elements absorbed in water $\mathrm{mg} / \mathrm{kg}(\mathrm{ppm})$ for the samples (1-3) of tobacco smoke.

\begin{tabular}{||c||c||c|c|c|c||c||c||c||c||}
\hline Sample & Ni & Al & Cr & Mg & Fe & Cd & Zn & K & Pb \\
\hline \hline 1 & 0.06 & 6.20 & $<1$ & 3.80 & $<1$ & $<1$ & 0.06 & 39.8 & $<1$ \\
\hline 2 & 0.05 & 5.50 & $<1$ & 1.20 & $<1$ & $<1$ & 0.01 & 20.6 & $<1$ \\
\hline 3 & 0.09 & 6.70 & $<1$ & 6.30 & $<1$ & $<1$ & 0.55 & 44.0 & $<1$ \\
\hline \hline
\end{tabular}

\section{4-Conclusion}

The selected types of cigarette from Iraqi markets were tested in EDX. Results proved the presence of dangerous elements such as (Ni, Zn, P, Pb, Cd, Si, S, Cr, As, Al, Sb and $\mathrm{Sn})$.), which greatly affect the health of the smoker and its negative effects to the environment. The genuine risk lies as those elements accumulate in the body of the smoker's lungs, liver, blood or brain and its effects are chronic and more dangerous and threaten the life of the person in the future.

\section{5-Acknowledgment}

We would like to acknowledge the Department of Chemistry, College of Science, Al-Nahrain University for encouragement and help and for the Department of Physics, College of Science for assistance and scientific support.

\section{6-References}

[1] Al-Zuhairi A., Al-Dahhan W., Hussein F.; Rodda K., Yousif E. "Teaching Laboratory Renovation", Oriental Journal of Physical Sciences, 1, 31-35, 2018.

[2] Ali A., Shaalan N., Al-Dahhan W., Yousif E., "For a Safer Working Environment with Hydrofluoric Acid in Iraqi Industrial Plants", Open Journal of Safety Science and Technology, 6, 77-80, 2016.

[3] Shireen R., Al-Dahhan W., Al-Zuhairi A., Hussein F., Rodda K., Yousif, "Fire and Explosion Hazards Expected in a Laboratory", Chemical Journal of Laboratory Education, 4, 35-37, 2016.

[4] Al-Dahhan W., Al-Zuhairi A., Hussein F., Rodda K., Yousif E., "Laboratory biological safety cabinet (BSC) explosion", Karbala International Journal of Modern Science, 2, 276-279, 2016.

[5 ] Al-Zuhairi A., Al-Dahhan W., Hussein F., Rodda K.,Yousif E., "A Vision to Promote the Forensic DNA Facility at Al-Nahrain University in Terms of Safety Measures", Oriental Journal of Physical Sciences, 2, 37-41, 2017.

[6] Mike M., Keeping Lab Air Safe, https://www.labcompare.com/343313-

Keeping-Lab-Air-Safe/, (2017).

[7] Memon A. R., Aktopraklig«1, D., Özdem «r A., Vertii A., "Heavy,metal accumulation and detoxification mechanisms in plants", Turkish Journal of Botany 25, 111- 121, 2001.

[8] Lars J., "Hazards of heavy metal contamination", Department of Epidemiology and Public Health, Imperial College, London, UK, http://bmb.oxfordjournals.org/

[9] Memon A., Aktoprakligül D., Demur A., Vertii T., "Heavy Metal Accumulation and Detoxification Mechanisms in Plants", Turkish Journal of Botany, 25, 111-121, 2001.

[10] Lougon A., Zhang M., Gadani F., Rossi L., Koller D., Kauss M., Wagner G., "Critical review of the science and options for reducing cadmium in tobacco", Advances in agronomy. Academic, New York, 111-180, 2004.

[11] Urios A., Lopez-Gresa M., Gonzalez M.; Primo J., Martinez A., Herrera G., "Nitric oxide promotes strong cytotoxicity of phenolic compounds against Escherichia 
coli: the influence of antioxidant defenses". Free RadicBiol Med 35, 1373-1381, 2003.

[12] Galazyn-Sidorczuk, M., Oska, M., Moniuszko-Jakoniuk, J., "Estimation of Polish cigarettes contamination with cadmium and lead, and exposure to thesemetals via smoking, Environmental Monitoring and Assessment", 137, 481493, 2008.

[13] Erzen I., Kragelj L., "Cadmium concentrations in blood in a group of male receruits in Solvenia related to smoking habits, Bulletin of Environmental Contamination and Toxicology", 76, 278284, 2006.

[14] Al-Bader A., Omu A., Dashti H., "Chronic cadmium toxicity to sperm of heavy cigarette smokers: immunomodulation by zinc", Archives of Andrology, 43, 135-140, 1999.

[15] Rey M., Turcotte F., Lapointe C., Dewailly E., "High blood cadmium levels are not associated with consumption of traditional food among the inuit of Nunavik", Journal of Toxicology and Environmental Health, Part A, 51,5-14, 1997.

[16] Shaham J., Meltzer A., Ashkenazi R., Ribak J., "Biological monitoring of exposure to cadmium, a human carcinogen as a result of active and passive smoking", Journal of Occupational and Environmental Medicine, 38, 1220-1228,1996.

[17] Paakko P., Anttila S., Kalliomaki P., "Cadmium and chromium as markers of smoking in human lung tissue", Environmental Research, 49, 197-207, 1989.

[18] Kjellstrom T., "Exposure and accumulation of cadmium in populations from Japan, the United States, and Sweden", Environmental Health Perspectives, 28, 169-197, 1979.

[19] International Agency for Research on Cancer (IARC).Tobacco Smoking, IARC Monograph 38, International Agency of Research on Cancer, Lyon, France (1986).

[20] Qamar W., Al-Ghadeer A., Ali R., "Analysis of Toxic Elements in Smoked Shisha Waterwaste and Unburnt Tobacco by Inductively Coupled Plasma-Mass Spectrometry: Probable Role in
Environmental Contamination", Research Journal of Environmental Toxicology, 9,4, 204-210, 2015.

[21] Ali A., Shaalan N., Al-Dahhan W., Hairunisa N., Yousif E., "A Technical Evaluation of a Chemistry Laboratory: A Step Forward for Maintaining Safety Measures", Oriental Journal of Physical Sciences, 2, 68-71, 2017.

[22] Hussein F., Al-Dahhan W., Al-Zuhairi A., Rodda K.,Yousif E., "Maintenance and Testing of Fume Cupboard". Open Journal of Safety Science and Technology, 7, 6975, 2017.

[23] Ibrahim A., Yousif E., ALShukry A., AlZuhairi A., "Hazard Analysis and Critical Control Point HACCP System". Iraqi National Journal of Chemistry 16, 172-185, 2016.

[24] Yousif E., Al-Dahhan W., Abed R., AlZuhairi, A, Hussein F., "Improvement of A Chemical Storage Room Ventilation System", Journal of Progressive Research in Chemistry, 4, 206-210, 2016.

[25] Yousif E., Al-Dahhan W., Ali A.; Rashad A., Akram E., "Mind What You Put in a Furnace: A Case Study for a Laboratory Incident", Journal of Environmental Science and Public Health, 1, 56-61, 2017.

[26] Sebiawu G., Mensah N., Mensah F., "Analysis of Heavy Metals Content of Tobacco and Cigarettes sold in $\mathrm{Wa}$ Municipality of Upper West Region, Ghana”. Chemical and Process Engineering Research, 25, 24-34, 2014. 